\title{
"Descapitalización Humana en los Institutos Nacionales, como producto de las Migraciones en El Salvador"
}

Por Elsa Ramos

El tema migración a pesar de que es un tema de gran importancia desde hace muchos años para El Salvador, es hasta hace muy poco que se le está asignando el lugar que le corresponde, tanto en los medios de comunicación social (MCS); diferentes organizaciones no gubernamentales (ONG); el gobierno central con la creación de un Viceministerio de Relaciones Exteriores para los Salvadoreños en el Exterior (2004); el surgimiento de la Mesa Permanente para las Personas Migrantes de la Procuraduría para la Defensa de los Derechos Humanos de El Salvador; la elaboración del Informe de Desarrollo Humano de El Salvador 2005 (IDHES, 2005), dedicado íntegramente al impacto de las migraciones en EI Salvador; varias universidades privadas también están realizando investigaciones en diferentes temáticas relacionadas con la migración.

A medida que transcurre el tiempo, el tema de las migraciones internacionales en el pais adquiere mayor relevancia, pues como afirma el Informe de Desarrollo Humano (IDHES) 2005 , del Programa de las Naciones Unidas para el Desarrollo (PNUD), las migraciones han transformado el país de forma profunda, El Salvador no se puede pensar, imaginar y planificar sin tomar en cuenta este factor. No es en vano dicha consideración, si se tiene en cuenta, que de acuerdo a datos cualitativos del Ministerio de Relaciones Exteriores, en total se encuentran fuera del pais 2.9 millones de salvadoreños, que el mayor número de ellos, se concentran en los Estados Unidos de América, en donde alcanzan la cifra aproximada de 2.6 millones. Este gran número de compatriotas en el exterior, sólo entre el año 2005 y 2006 , han aportado a la economia nacional $\$ 2,830.2$ y $\$ 3,315.7$ millones de dólares respectivamente. Las cifras anteriores representan aproximadamente el 16 y el 19 por ciento del PIB en dichos años, cabe agregar

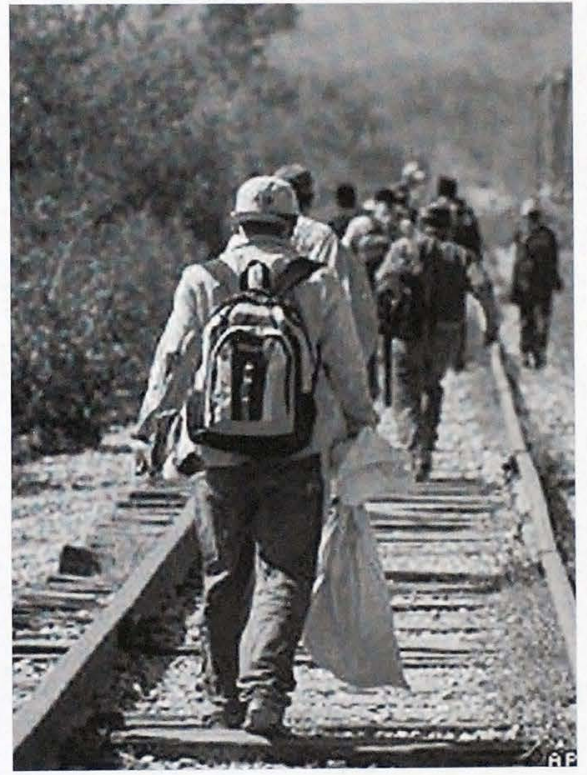

entorno

Entorno ISSN: 2218-3345 
"Descapitalización Humana en los Institutos Nacionales, como producto de las Migraciones en El Salvador"

pp. $49-52$

Ramos, E.

Universidad Tecnológica de El Salvador - Agosto 2007 - N². 38

asimismo que entre 1997 y el año 2006 el pais recibió más de 20 mil millones de dólares norteamericanos, de acuerdo a datos aportados por el Banco Central de Reserva (BCR), y que han contribuido a que los niveles de pobreza extrema y relativa en el país no crezcan más. Es importante señalar que las cifras anteriores son cifras oficiales, pero que el nivel de remesas recibido en el país es aún mayor, pues no se toman en cuenta los dólares que son enviados a las familias salvadoreñas a través de los encomenderos, familiares y amigos cercanos cuando estos visitan el país. Las remesas no sólo se han utilizado para subsanar las necesidades más inmediatas de las familias, como son la alimentación, el vestido, calzado, servicios básicos; sino que parte importante de ellas se han invertido en la educación de los hijos que se quedan, desde la parvularia hasta carreras de pre grado en las universidades del país, o sea, hay una importante inversión en capital humano gracias a dichas remesas, sin mencionar varias áreas de la economía nacional que también se han desarrollado gracias a éstas.

Sin embargo, a pesar de todos estos esfuerzos realizados a la fecha, se puede afirmar que el tema sobre las migraciones en el país, apenas se comienza a estudiar y que es necesario y pertinente profundizar los temas que ya se han estudiado e incluir nuevas temáticas, pues ello contribuirá no sólo a entender de forma más amplia el fenómeno; sino que dará las luces necesarias para que la nación y sus diversas instituciones, las gubernamentales en primera instancia, tomen las medidas necesarias, para que se le ponga fin a la perdida de recursos humanos que está sufriendo el país, que se deje de ser un país expulsor de población y que se busquen los mecanismos necesarios, para eliminar las causas que motivan a los salvadoreños a buscar otros horizontes fuera de su hogar, su tierra y su patria.

La Universidad Tecnológica de El Salvador (UTEC), a través de la Vicerrectoria de Investigación y Proyección Social (VIPS), consciente de la importancia y retos que representa el estudio del fenómeno migratorio en el pais, ha desarrollado como parte de su programa de trabajo en el año 2006, la investigación "Descapitalización Humana en los Institutos Nacionales, como producto de las Migraciones en EI Salvador", cuyo objetivo principal es detectar la tendencia de los alumnos de bachillerato de los Institutos Nacionales, que tienen la intención de emigrar una vez finalizados sus estudios $y$, con ello contribuir en la profundización de los estudios del fenómeno migratorio.

Al carecer de datos estadísticos consolidados acerca de ésta temática y la ausencia de estudios especíicos que aborden esta problemática, el carácter de esta investigación es exploratoria, aplicando una metodologia de tipo cuantitativa y cualitativa. Se tomó una muestra intencional, que consistió en la administración de un cuestionario con preguntas cerradas y abiertas a los estudiantes de un grupo de bachillerato, de institutos nacionales en los 14 departamentos que conforman el pais, asimismo se realizó una pequeña entrevista semi-estructurada a las autoridades de los institutos nacionales que formaron parte de la muestra.

Como ya se mencionó en el párrafo anterior, el estudio ha sido exploratorio de la tendencia estadistica observada en los estudiantes de los Institutos Nacionales del pais, en cuanto a su perspectiva de migrar hacia los Estados Unidos de Norteamérica una vez hayan concluido sus estudios de bachillerato, incluye asimismo la correlación existente entre los estudiantes que emigraran y las redes sociales con que cuentan en ese pais; las causas principales que los motivan a desear emigrar; que estudios adicionales han realizado en vista a su mejor integración al mercado laboral norteamericano; qué porcentaje de hombres y de mujeres quieren emigrar; viajarán de forma documentada o no; los que viajarán de forma indocumentada harán uso o no de los servicios de 
los guías (conocidos popularmente como "coyotes") y la actitud mostrada por los estudiantes ante el endurecimiento de las medidas migratorias de los EE.UU. en contra de la migración indocumentada.

La presente investigación se ha visto fortalecida gracias a la observación y contacto directo con diversas ONG que trabajan de forma directa con población emigrante, deportados y población en tránsito; de las diferentes visitas que se han realizado al Aeropuerto Internacional de Comalapa y a la Frontera de La Hachadura por los miembros de la Mesa de Emigrantes, de la cual forma parte UTEC, a observar y encuestar a los deportados provenientes de EE.UU. (vía aérea) y de México, y constatar in situ, lo que ya algunos representantes de ONGs que trabajan el tema migratorio y algunos estudiosos del tema, han expresado, acerca de que el segmento de población que más esta emigrando, es el grupo etario comprendido entre los 15 y los 24 años de edad; que una gran parte de estos emigrantes ya no provienen del sector rural, sino del sector urbano; que cada dia aumenta más el número de mujeres que emigran; que el grado de escolaridad de estas personas
Es importante señalar que actualmente la riqueza de un país ya no se mide necesariamente a partir de la cantidad de recursos naturales que éste posea, sino a partir de la mayor o menor cantidad de capital humano con que cuente éste; se afirma también que es el capital humano el que permite que un pais sea competitivo y que pueda insertarse de forma favorable y ventajosa al proceso de globalización en el que actualmente se desarrolla la sociedad humana.

Analizar esta problemática es de suma importancia para el país, pues es de sobra conocido, que el progreso, la competitividad y desarrollo humano de un pais, se sustenta en gran medida, en la formación de recursos humanos o capital humano como se le denomina actualmente, si estos últimos emigran, implica que el país se empobrece, que prematuramente y de forma artificial se envejece su población desde el punto de vista demográfico, todo ello en detrimento de la población joven que se quede, pues serán ellos los que tendrán que hacerle frente en gran medida a los costos materiales, sociales y psicológicos de una población envejecida. supera los 6 años en promedio, dato que resulta alarmante, porque significa que una parte importante de los recursos que invierte el Estado a través del Ministerio de Educación (MINED), las familias residentes en El Salvador y los padres, parientes 0 amigos en el exterior en el rubro educación, o sea, en la capitalización humana ${ }^{1}$, se están perdiendo, por efecto de la masiva emigración de salvadoreñas y salvadoreños al exterior, principalmente a los EE.UU.

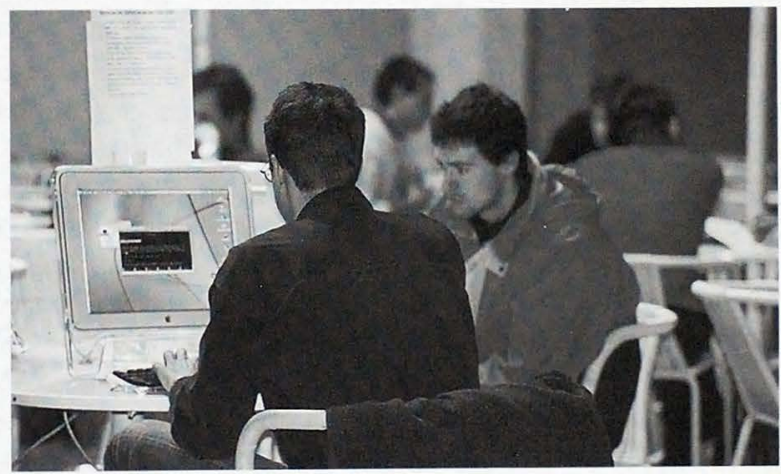

' Capital Humano, es el valor que generan las capacidades de las personas mediante la educación, la experiencia, la capacidad de conocer, de perfeccionarse, de toma decisiones y de relacionarse con los demás. El capital humano es el cúmulo de conocimientos y habilidades que poseen los individuos y su capacidad para aplicarlos a los sistemas productivos. La descapitalización humana sería el proceso mediante el cual un pais pierde sus recursos humanos especialmente a través de los procesos migratorios internacionales. 
"Descapitalización Humana en los Institutos Nacionales, como producto de las Migraciones en El Salvador"

pp. $49-52$

Ramos, E.

Universidad Tecnológica de El Salvador - Agosto 2007 - №. 38

A continuación se presentan algunos de los datos obtenidos como producto de dicha investigación:

De una muestra total de 514 estudiantes, 136 de ellos manifestaron que tienen la intención de emigrar de el pais una vez concluyan sus estudios de bachillerato, obteniendo asi que un 26.45 por ciento de la población estudiantil de ambos sexos de los bachilleratos de los Institutos Nacionales de la muestra quieren emigrar.

De esos 136 jóvenes que desean emigrar, 76 de ellos son del sexo masculino y 60 del sexo femenino, lo que equivale a que un 55.88 por ciento de la muestra son hombres y 41.11 por ciento son mujeres; ese dato confirma las percepciones de los analistas, que la tendencia de los años 80 s y 90 s del siglo recién pasado, se esta revirtiendo, en el sentido que, si en esas épocas entre el 80 y 90 por ciento de los emigrantes eran hombres, ahora, año con año es mayor la cantidad de mujeres que intentan emigrar; además y de acuerdo a los datos arrojados en las entrevistas con los directores o subdirectores, más de la mitad de ellos opinó, que en la actualidad la tendencia migratoria entre hombres y mujeres es casi paritaria, o sea, un 50 por ciento de hombres y un 50 por ciento de mujeres.

En relación a las zonas 0 áreas de donde provienen los jóvenes que desean emigrar, es también revelador, ya que prácticamente el 56 por ciento proviene de las área urbanas y sólo un 41 por ciento de las áreas rurales, hecho que también muestra una tendencia diferente a la de las dos décadas anteriores en donde prevalecian los inmigrantes de origen rural.

Se puede añadir que un 35.29 por ciento de los estudiantes que desean emigrar, reciben remesas para estudiar, ya sea de sus padres, parientes cercanos 0 amigos cercanos, lo que indica que, parte importante de las remesas se invierte en la formación de capital humano, que el Ministerio de Educación también invierte, en la educación de esos jóvenes y sin embargo, al no encontrar los alicientes necesarios, como poder tener acceso a trabajos decentes, mayores oportunidades de formación profesional, mejores salarios, y otros, estos jóvenes no encuentran una salida viable a sus aspiraciones de superación personal, lo que los obliga, a tomar como alternativa a la resolución de sus problemas vitales, la migración hacia los EE.UU, porque es el país más cercano relativamente, se puede viajar vía terrestre y porque también la mayoria de estos jóvenes, cuentan con alguno de sus progenitores, si no es que a ambos, parientes y amigos cercanos, que les ayudarán a solventar los gastos que implica emprender el viaje de los indocumentados.

Entre los resultados obtenidos en el trabajo de campo y, que atañen a la descapitalización humana, se tiene que de la muestra, el 26.45 por ciento de los y las estudiantes desean emigrar hacia los EE.UU. todos sin excepción ya tienen más 9 años de escolaridad (son estudiantes que están cursando el primero, segundo 0 tercer años de bachillerato); el 59.79 de ellos y ellas han estudiado inglés, específicamente para prepararse para emigrar y un 20 por ciento han estudiado cursos adicionales, para que les sea más fácil incorporarse al mercado laboral norteamericano y con vistas a recibir mejores salarios. Surge de ahi la interrogante ¿Cuánto esta perdiendo el Estado salvadoreño cuando estos jóvenes emigren? ¿Cuántos perderán la vida ó alguno de sus miembros en busca del sueño americano?; tomando en cuenta que el 56 por ciento de esos hoy estudiantes de bachillerato, declaran que viajaran de forma indocumentada y acompañados por un coyote. Los comentarios están demás.

Lo anterior constituye una muestra de los resultados obtenidos en la investigación "Descapitalización Humana en los Institutos Nacionales, como producto de las migraciones en El Salvador". 